\title{
Measurement of Velocity and Temperature Profiles in the 1/40 Scaled-Down CANDU-6 Moderator Tank
}

\author{
Hyoung Tae Kim, ${ }^{1}$ Jae Eun Cha, ${ }^{1}$ Han Seo, ${ }^{2}$ and In Cheol Bang ${ }^{2}$ \\ ${ }^{1}$ Korea Atomic Energy Research Institute, 989-111 Daedeok-daero, Yuseong-gu, Daejeon 305-353, Republic of Korea \\ ${ }^{2}$ Ulsan National Institute of Science and Technology, Ulsan, Republic of Korea
}

Correspondence should be addressed to Hyoung Tae Kim; kht@kaeri.re.kr

Received 8 October 2014; Accepted 23 January 2015

Academic Editor: Ali Hainoun

Copyright (c) 2015 Hyoung Tae Kim et al. This is an open access article distributed under the Creative Commons Attribution License, which permits unrestricted use, distribution, and reproduction in any medium, provided the original work is properly cited.

\begin{abstract}
In order to simulate the CANDU-6 moderator circulation phenomena during steady state operating and accident conditions, a scaled-down moderator test facility has been constructed at Korea Atomic Energy Institute (KAERI). In the present work an experiment using a 1/40 scaled-down moderator tank has been performed to identify the potential problems of the flow visualization and measurement in the scaled-down moderator test facility. With a transparent moderator tank model, a flow field is visualized with a particle image velocimetry (PIV) technique under an isothermal state, and the temperature field is measured using a laser induced fluorescence (LIF) technique. A preliminary CFD analysis is also performed to find out the flow, thermal, and heating boundary conditions with which the various flow patterns expected in the prototype CANDU-6 moderator tank can be reproduced in the experiment.
\end{abstract}

\section{Introduction}

The CANadian Deuterium Uranium (CANDU) reactor has a square array of horizontal fuel channels surrounded by heavy water moderator contained in a horizontal, cylindrical tank called a calandria. Each fuel channel consists of two concentric tubes, a pressure tube (PT) inside a calandria tube (CT), with a gap that contains $\mathrm{CO}_{2}$ insulating gas. As a CANDU reactor has a high pressure primary cooling system and an independently cooled moderator system, the moderator in the calandria would act as a supplementary heat sink during a loss of coolant accident (LOCA) if the primary cooling and emergency coolant injection systems fail to remove the decay heat from the fuel.

The CANDU industry had widely accepted that fuel channel integrity could be ensured if the moderator available subcooling at the onset of a large LOCA is greater than the subcooling requirements. The premise of this approach is based on a series of contact boiling experiments [1] which derived the subcooling requirements [2] to preclude a sustained calandria tube dryout by the minimum available moderator subcooling and the pressure tube/calandria tube contact temperature. The local temperature of the moderator is a key parameter in determining the available subcooling. However, in order to predict the moderator temperature distribution, numerous experimental and numerical studies have been performed, because only the inlet/outlet temperature can be measured in the real CANDU reactor. The moderator temperature distribution in the calandria is developed as a result of the flow patterns and circulation characteristics which themselves are generated as a result of interactions between the inertia forces (arising from inlet jets) and buoyancy forces (arising from heat generation) in the calandria.

To study the moderator circulation phenomena in a CANDU reactor, KAERI started experimental research on moderator circulation as one of a national R\&D research programs from 2012. This research program includes the construction of the moderator circulation test (MCT) facility [3], production of the validation data for self-reliant CFD tools, and development of an optical measurement system using particle image velocimetry (PIV) [4] and laser induced 


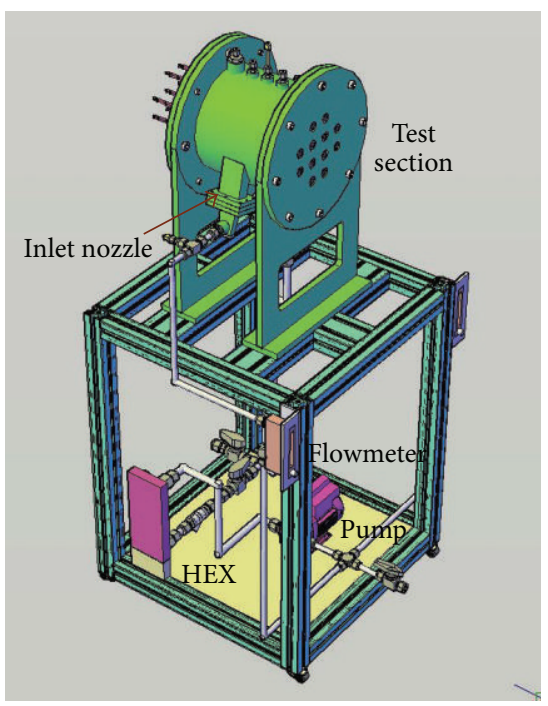

Figure 1: 1/40 scaled-down test facility for CANDU-6 moderator tank.

fluorescence (LIF) techniques. Small-scale $1 / 40$ and 1/8 smallscale model [3] tests were performed prior to installation of the main MCT facility to identify the potential problems of the flow visualization and measurement expected in the $1 / 4$ scale MCT facility.

For the present study a flow field is measured with a PIV measurement technique under an isothermal state, and the temperature field is visualized using a LIF technique in the $1 / 40$ scaled-down moderator tank. In the PIV system a NdYAG double-cavity laser [5] beam comes from the vertical side of a CCD camera. A light sheet is created in the tank, and traces of particles that react with a laser are visualized and captured to obtain the velocity profile by computer system. A preliminary CFD analysis is also performed to find out the flow, thermal, and heating boundary conditions with which the various flow patterns expected in the prototype CANDU6 moderator tank can be reproduced in the experiment.

\section{1/40 Scaled-Down Test Facility}

Figures 1 and 2 show the 1/40 scaled-down test facility and cross-sectional view of the test section, respectively.

The test section is a scaled-down tank model by the corresponding scaling ratio, having an inner diameter of $180 \mathrm{~mm}$ and an axial length of $200 \mathrm{~mm}$. The simulator of a calandria tube in the moderator tank consists of 12 electric heaters with a $17.3 \mathrm{~mm}$ outer diameter and $3 \mathrm{~kW}$ design power. The pitch of the heater rods is $37 \mathrm{~mm}$, and this geometric scale preserves the actual porosity, 0.83 of the CANDU- 6 moderator tank. The heater power is controlled such that the set point of the K-type thermocouple temperature on the outer surface of the heater may not be exceeded. The surface of the heater is black colored to reduce the refraction of light, and both end plates of the tank are made of polycarbonate, which is good at visualization and heat insulation. Distilled water $\left(\mathrm{H}_{2} \mathrm{O}\right)$ is used in the test as a working fluid instead of heavy water in the CANDU-6 moderator tank. Water is circulated by a DCpower pump and heated by 12 heater rods and cooled by a plate-type heat exchanger with a maximum cooling capacity of $10 \mathrm{~kW}$. The inlet water temperature is controlled by the heat removal rate in the water reservoir in the secondary side of the heat exchanger. The inlet flow rate is measured using a Rotameter with $\pm 1 \%$ of uncertainty. The flow balance between the two inlet nozzles is maintained by adjusting the opening of the flow valves installed at each side. Two inlet nozzles are located near the horizontal middle plane of the tank and fitted with slit nozzles that point upwards. Water flows in through these slit inlet nozzles and goes out through an exit nozzle located at bottom of the tank.

The temperature measurements inside the tank are performed at 3 different axial locations (center, $65.4 \mathrm{~mm}$ apart from both ends). For each axial location, 3 different measurement points are at the center, $5 \mathrm{~mm}$ below the top, and $5 \mathrm{~mm}$ above the bottom of the tank. Therefore, there are 9 measurement points inside the tank. Additionally two inlet temperatures and one outlet temperature are measured.

\section{Preliminary CFD Analysis}

It is known that the flow patterns inside the moderator tank can be identified into three types of flow, that is, momentum dominant flow, mixed-type flow, and buoyancy dominant flow, according to the ratio of buoyancy force (arising from internal heating) to inertia force (arising from the inlet jet) as shown in Figure 3. In the present work, these 3 flow patterns are simulated by the CFD analysis using the fixed boundary conditions of inlet flow rate and heating power.

CFX version 13.0 [6] is used in the present CFD analysis. CFX-13.0 is based on the finite volume method (FVM) modified with the shape function used in finite element methods (FEM) to make the construction of a node-centered computation possible. This is different from FLUENT using a classical cell-centered FVM scheme.

The governing equations consist of conservative laws on mass, momentum, and energy. They are written as follows in tensor form:

$$
\begin{gathered}
\frac{\partial \rho}{\partial t}+\frac{\partial}{\partial x_{j}}\left(\rho U_{j}\right)=0 \\
\frac{\partial}{\partial t}\left(\rho U_{i}\right)+\frac{\partial}{\partial x_{j}}\left(\rho U_{i} U_{j}\right)=-\delta_{i, j} \frac{\partial p}{\partial x_{j}}+\frac{\partial \tau_{i, j}}{\partial x_{j}}+S_{M i}, \\
\frac{\partial}{\partial t}\left(\rho h_{\mathrm{tot}}\right)-\frac{\partial p}{\partial t}+\frac{\partial}{\partial x_{j}}\left(\rho U_{j} h_{\mathrm{tot}}\right) \\
=\frac{\partial}{\partial x_{j}}\left(\lambda \frac{\partial T}{\partial x_{j}}\right)+\frac{\partial}{\partial x_{j}}\left(U_{j} \tau_{i, j}\right)+U_{i} S_{M i}+S_{E},
\end{gathered}
$$

where $\rho, U_{j}, p, \tau_{i, j}$, and $T$ are density, velocity vector, pressure, shear stress, and temperature, respectively, and the coefficient $\lambda$ is thermal conductivity. The shear stress tensor 

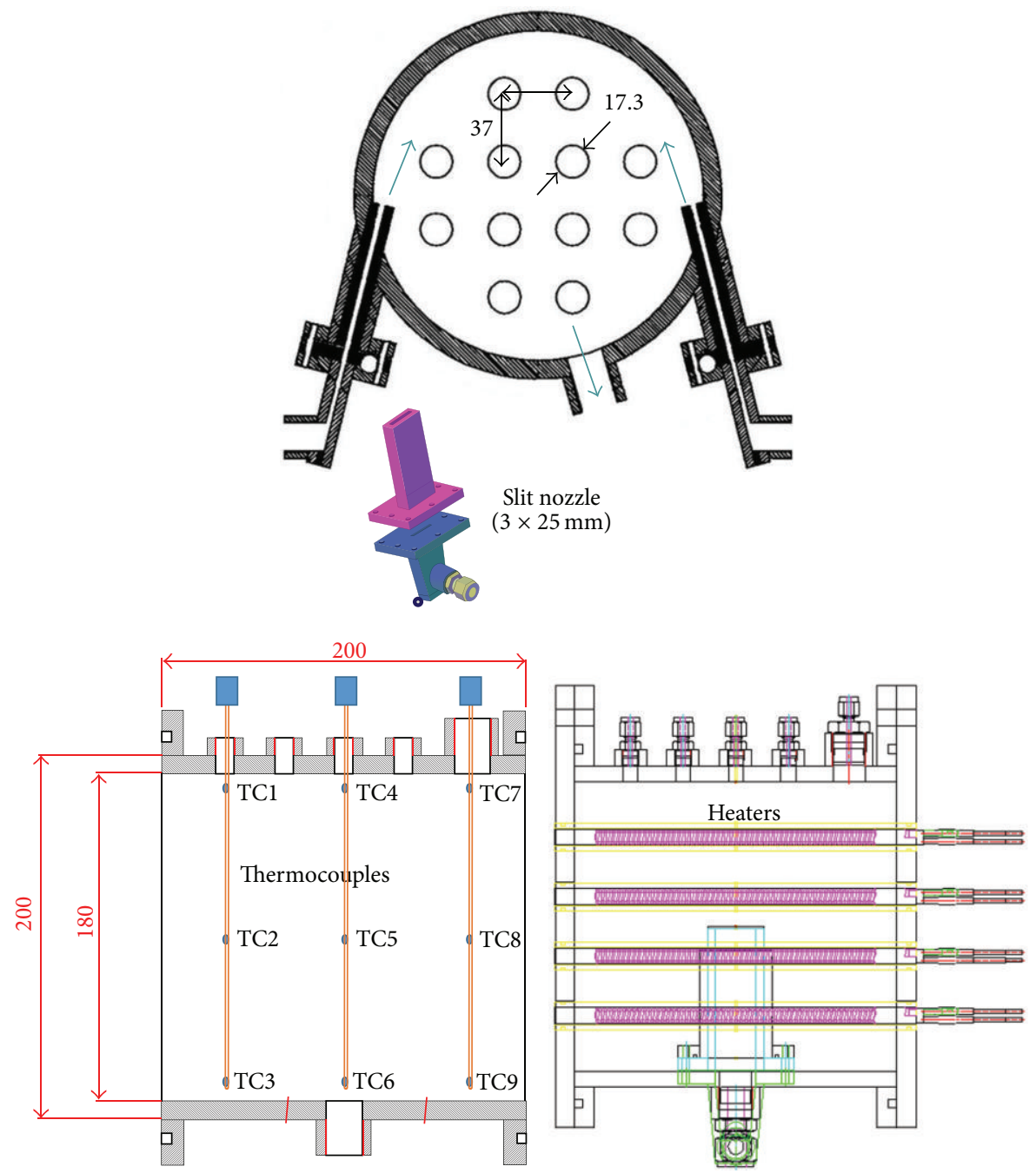

FIGURE 2: Test section and the measurement points.

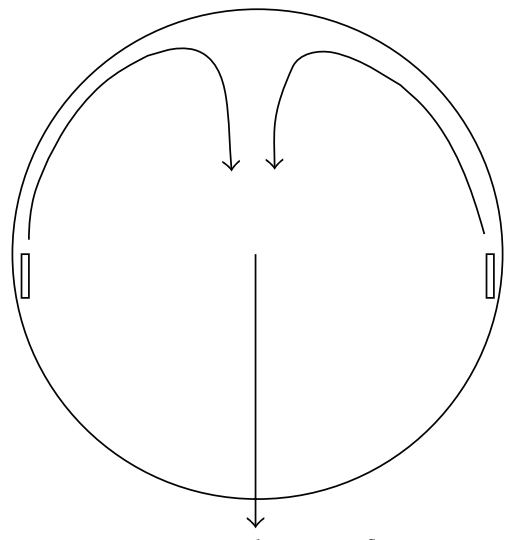

Momentum dominant flow

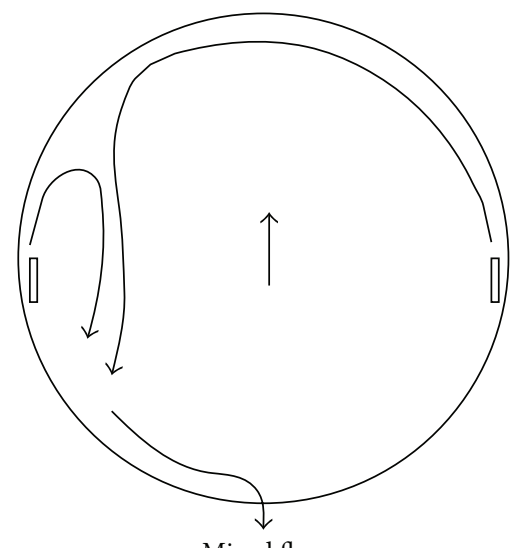

Mixed flow

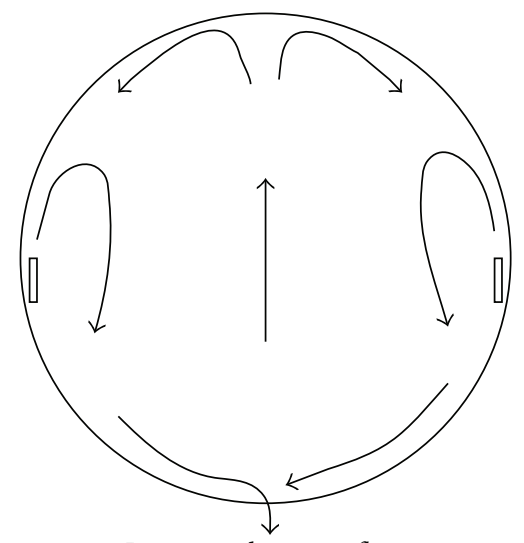

Buoyancy dominant flow

FIGURE 3: Flow characteristics in the moderator tank. 

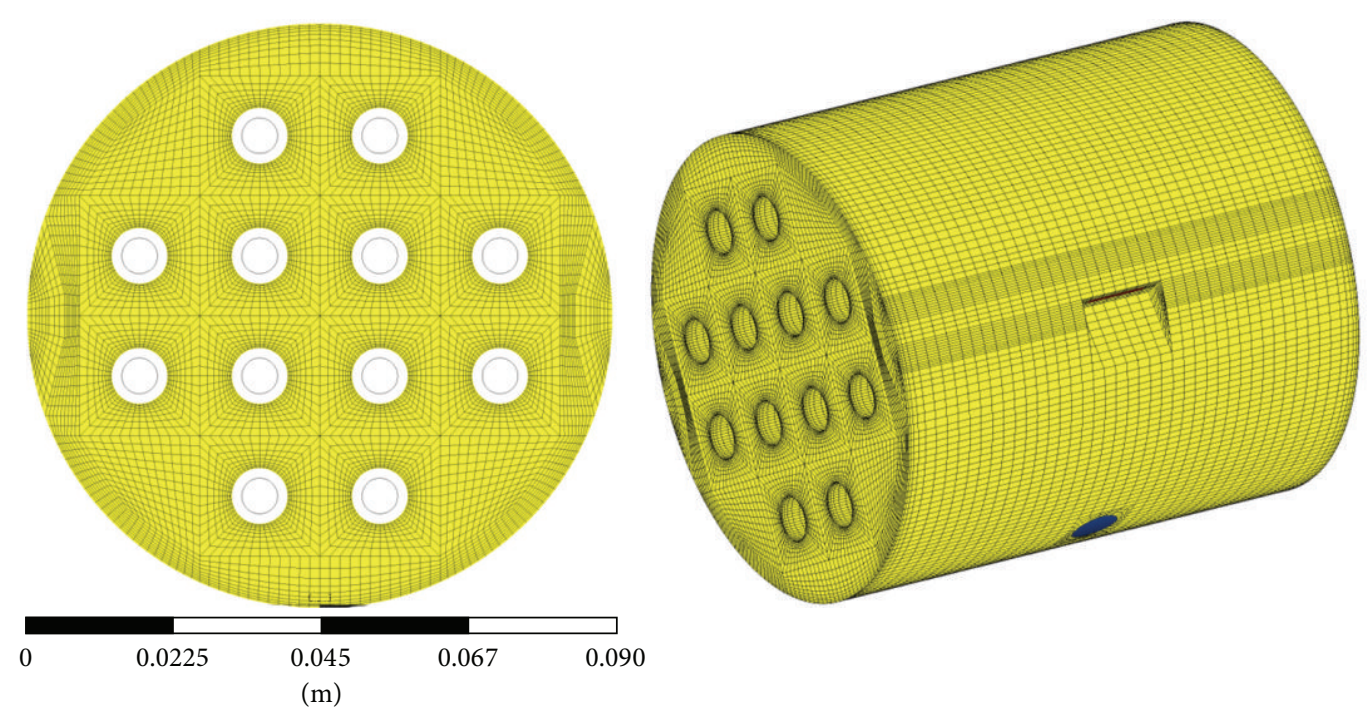

FIGURE 4: Mesh generation for 1/40 scaled-down test.

in (2) by the Navier-Stokes equation and total enthalpy, $h_{\text {tot }}$, in (3) by energy equation are defined as

$$
\begin{gathered}
\tau_{i . j}=\mu\left\{\left(\frac{\partial U_{i}}{\partial x_{j}}+\frac{\partial U_{j}}{\partial x_{i}}\right)-\frac{2}{3} \delta_{i, j} \frac{\partial U_{i}}{\partial x_{j}}\right\}, \\
h_{\mathrm{tot}}=h+\frac{1}{2} U_{j}^{2},
\end{gathered}
$$

where the coefficient $\mu$ is viscosity and $h=e+p / \rho$; $e$ is the internal energy per unit mass.

The boundary condition at the solid surface is a no-slip condition while the heat flux is given on the outer surface of the heater rods. The inlet condition specifies the mean mass flow rate, and the pressure is set to ambient at the outlet.

The $k-\varepsilon$ model with scalable wall functions is applied for turbulence model. The incident turbulence intensity is assumed to be $5 \%$, and turbulence length scale is set to the diameter of a tube.

From the scaling analysis [7], the flow pattern inside the moderator tank is determined depending on the ratio of the buoyancy to inertia forces, represented by the nondimensional Archimedes number (Ar), defined as

$$
A r=\frac{g \beta Q D}{\rho C_{p} A u^{3}},
$$

where $A$ is inlet nozzle area $\left[\mathrm{m} / \mathrm{s}^{2}\right], C_{p}$ is specific heat $\left[\mathrm{J} / \mathrm{kg}^{\circ} \mathrm{C}\right], D$ is diameter $[\mathrm{m}], Q$ is heater power $[\mathrm{W}], g$ is gravity constant $\left[\mathrm{m} / \mathrm{s}^{2}\right], u$ is inlet velocity $[\mathrm{m} / \mathrm{s}], \beta$ is thermal expansion coefficient, and $\rho$ is fluid density $\left[\mathrm{kg} / \mathrm{m}^{3}\right]$.

From (5), Ar number becomes 0.90, 0.21, and 0.06 for 3 different inlet flow rates 0.8 LPM, 1.3 LPM, and 2.0 LPM, respectively, for a heating power of $1.84 \mathrm{~kW}$. For the full power steady state operation conditions of the CANDU- 6 reactors, the Ar number is 0.21 , which results in a mixed-type flow in the moderator tank.
The CFX calculations with an inlet flow of 0.8 LPM, 1.3 LPM, and 2.0 LPM are performed to confirm that these 3 cases of calculations reproduce buoyancy dominant, mixedtype, and momentum dominant flows, respectively.

The mesh used for the present simulation adopts the full geometric details of the tube bundle. The mesh adjacent to the rod wall is fine enough to resolve the boundary layer flow as shown in Figure 4. The CFX modeling of the test facility is confined to the tank section with the inlet and outlet nozzle faces. The total number of nodes is 671,400 for this CFX modeling. The constant velocity boundary conditions corresponding to the specified flow rates are given to the inlet nozzle faces and the uniform heat flux boundary condition with $1.84 \mathrm{~kW}$ of total heating power to the heater surface.

The temperature and velocity distributions on the cross section of the tank are obtained from the steady-state solutions for 3 flow cases of 0.8 LPM, 1.3 LPM, and 2.0 LPM, as shown in Figure 5 . These cross-section views are on the axial middle plane of the tank.

For the case of 0.8 LPM, the inlet jets are weak relative to the buoyancy force. These jets do not penetrate the top of the tank, an instead turn around in the middle of the tophalf and flow down toward the outlet nozzle throughout the first and third column of tube bundles resulting in a buoyancy dominant upward flow throughout the center of the tube columns. This produces a stratified temperature distribution, where temperatures at the bottom of the tank are close to the outlet temperature, and temperatures at the top of the tank are significantly higher than the outlet temperature.

For the case of 1.3 LPM, the inlet jets reach the top of the tank, collide with each other a little left from the top center, and form downward moving flows. Since the jet collision occurs slightly asymmetrically, a larger recirculation loop is formed at the right side and a smaller one at the left side. The large recirculation loop pushes down the high temperature-zone from the top of the tank resulting in an 


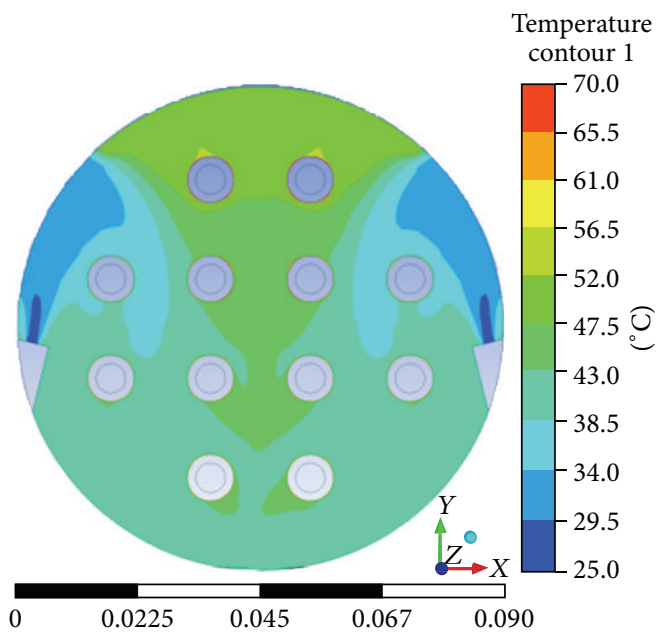

(m)

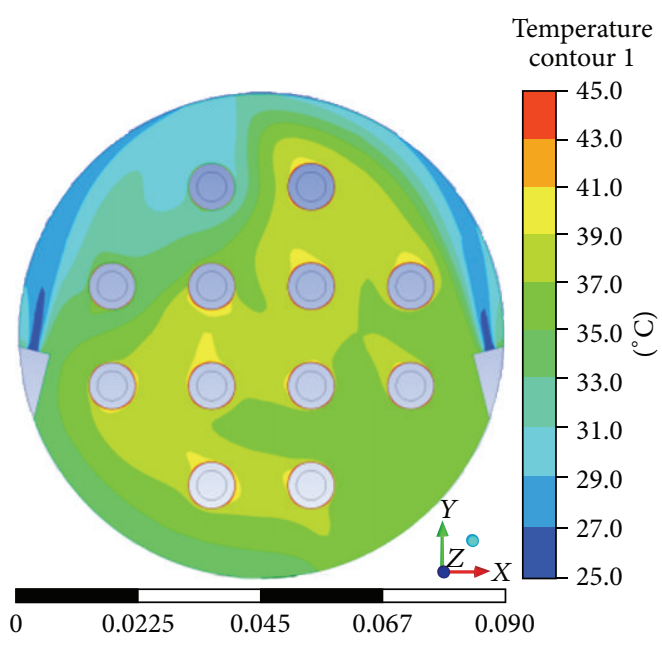

(m)

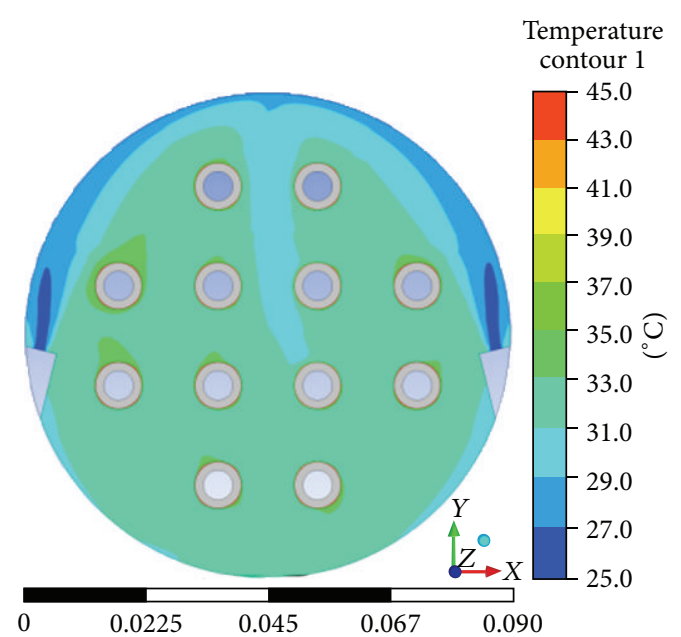

(m)

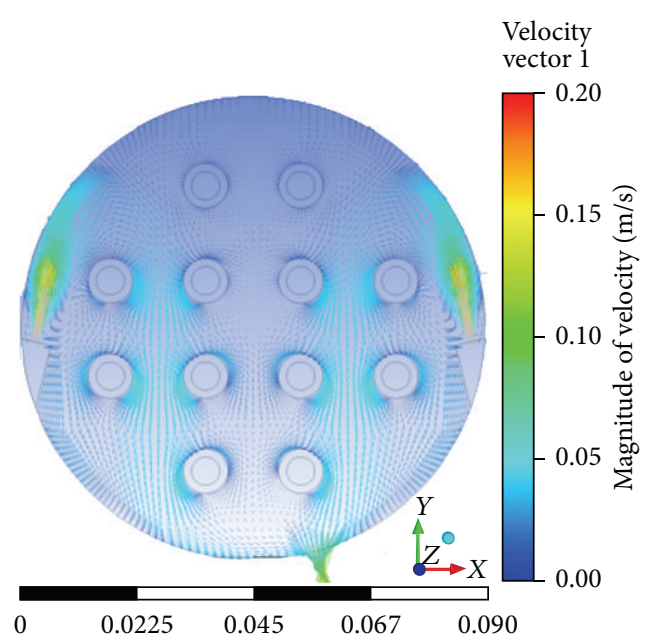

(m)

(a) $0.8 \mathrm{LPM}$

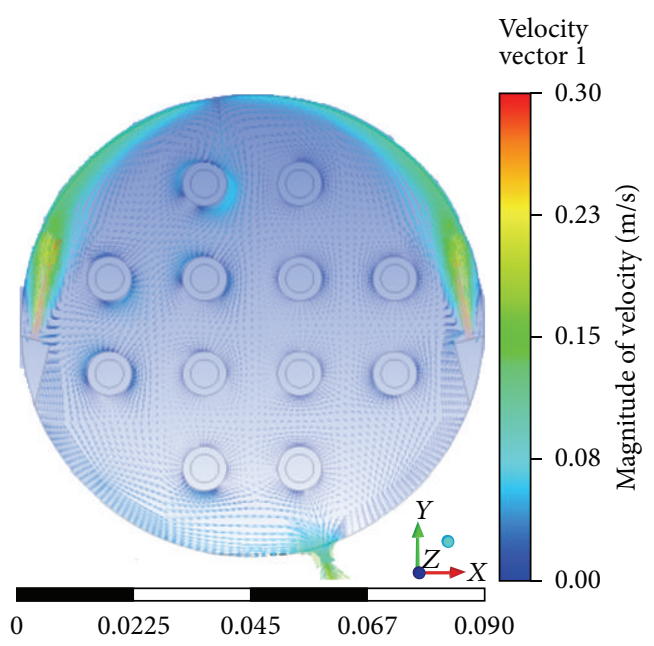

(m)

(b) $1.3 \mathrm{LPM}$

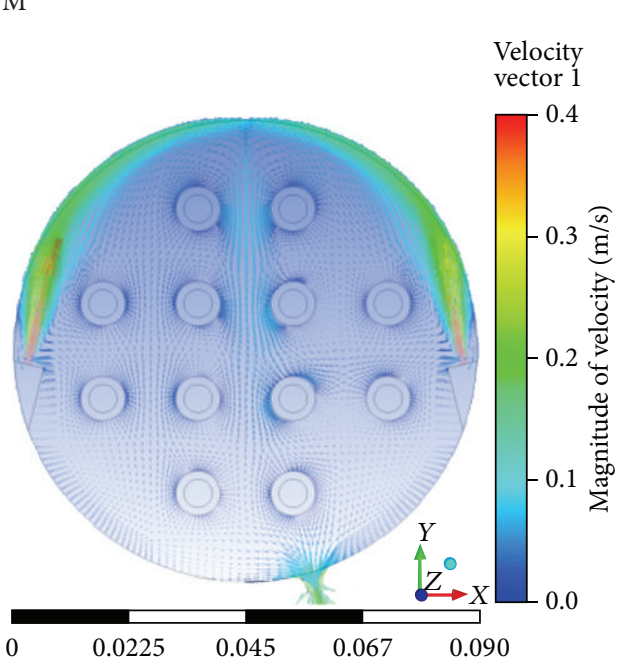

(m)

(c) $2.0 \mathrm{LPM}$

FIGURE 5: Temperature (left) and flow distributions (right) according to the flow boundary conditions in the CFD analysis. 


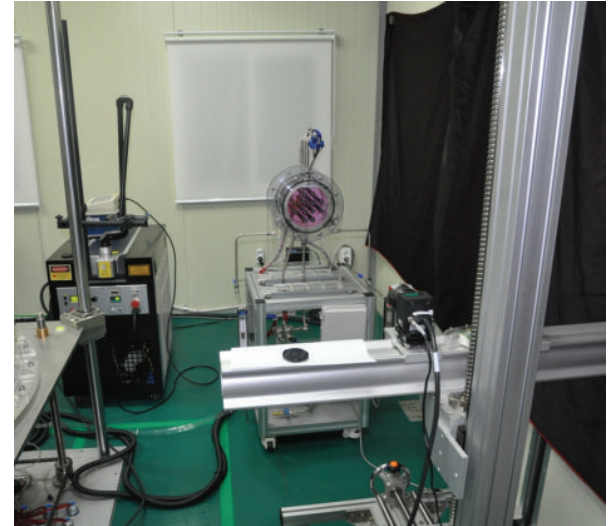

FIGURE 6: PIV and LIF system arrangement for the test facility of a 1/40 scaled-down moderator tank.

asymmetric temperature distribution. The peak temperature is significantly higher than the outlet temperature.

For the case of 2.0 LPM, the inlet jets are strong relative to buoyancy forces; they penetrate to the top of the tank and produce a downward flow through the center of the tube columns towards the outlet nozzle, with buoyancy driven recirculation loops on both sides. This results in a temperature field with the high temperature zone confined inside the recirculation loops. The peak temperature is slightly higher than the outlet temperature and is attained at an elevation well below the top of the tank. The flow and temperature are in symmetric distributions.

From the preliminary CFD analysis for a $1 / 40$ scaleddown test, we can confirm that the mixed-type of flow pattern observed in the CANDU-6 moderator tank during normal operation conditions [8] is reproduced by the CFD simulation using boundary conditions with $1.84 \mathrm{~kW}$ of heating power and 1.3 LPM of inlet flow rate, which preserves the same Ar number as the prototype. Other flow patterns such as the buoyancy flow and momentum dominant flow are shown to be reproduced by decreasing ( $0.8 \mathrm{LPM}$ ) or increasing (2.0 LPM) the inlet flow boundary condition, respectively.

\section{Experiment Works}

4.1. Flow Measurement. The PIV method is used to measure the velocity field inside the moderator tank. In this section, the preliminary measurement results by the PIV method in the 1/40 scaled-down moderator tank are introduced as a feasibility study of the PIV measurement for application to the moderator experiment.

Figure 6 shows the measurement arrangement for the 1/40 scaled-down model [3]. The arrangement consists of a TSI POWERVIEWTM Plus 2MP CCD camera and a Dual Nd-Yag laser with a $200 \mathrm{~mJ}$ capacity as a light source. INSIGHT $3 \mathrm{G}$ software is used to control the image capture and perform the data analysis. Silver coated hollow spheres $10 \mu \mathrm{m}$ in diameter as tracing particles and Rhodamine B spheres as a temperature-dependent fluorescent dye are

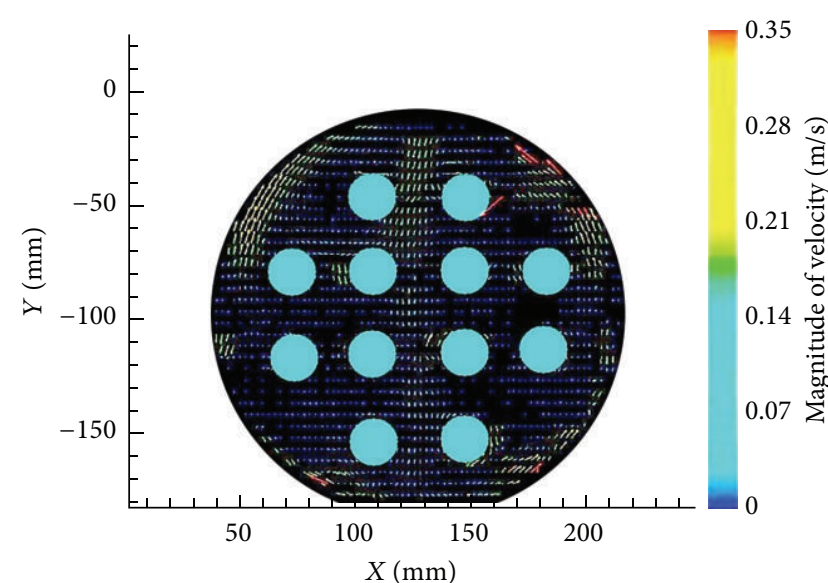

FIGURE 7: Velocity field at the inlet nozzle center plane (inlet flow rate of 2.2 LPM).

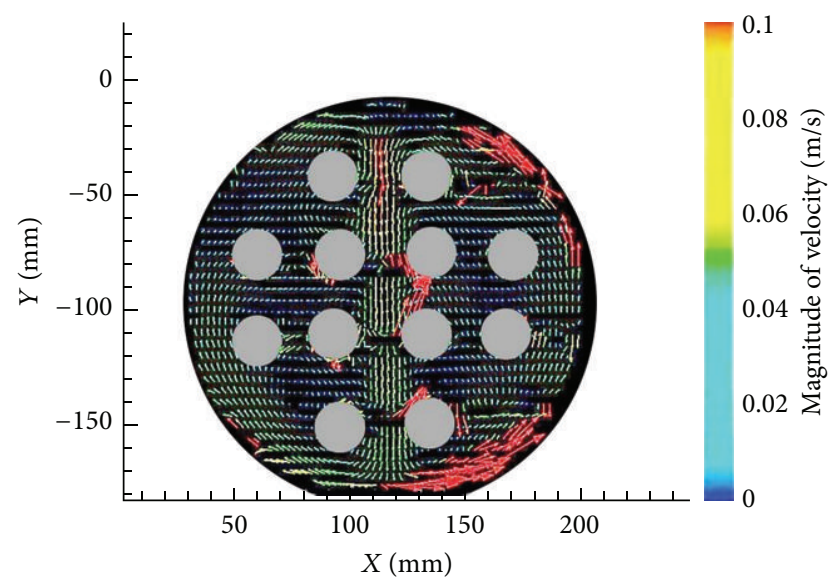

FIGURE 8: Velocity field at $40 \mathrm{~mm}$ from the inlet nozzle center plane (inlet flow rate of 2.2 LPM).

mixed in the water. A $610 \mathrm{~nm}( \pm 10 \mathrm{~nm})$ band-pass filter is placed in front of the camera to enhance the image quality.

Figures 7 and 8 show the velocity fields by the PIV in the cross-sectional planes. In Figure 7, the plane coincides with the inlet nozzle center plane. In Figure 8, the plane is $40 \mathrm{~mm}$ from the inlet nozzle center plane. The flow rate (for each two inlet nozzles) is 2.2 LPM, which is the maximum flow rate in the present circulation system. No heat is added to these preliminary tests. The water jets from the two inlet nozzles move up along the tank wall to the top and collide with each other, creating a stagnation point at the top of the tank. On the whole, the flow is symmetric; there are two counter-rotating flows. The inlet jet is spread from the inlet nozzle face and the maximum upward velocity measured at the inlet nozzle center plane is higher than that at $40 \mathrm{~mm}$ from the inlet nozzle center plane. The PIV flow image has a spatial resolution of $0.15 \mathrm{~mm} /$ pixel, and image analysis is conducted with a 32 pixel $\times 32$ pixel interrogation window.

There are tube bundle shadows in the particle image. The lack of tracing particles in the shadow regions as well as a curvature of the tank wall in the upper and lower part 


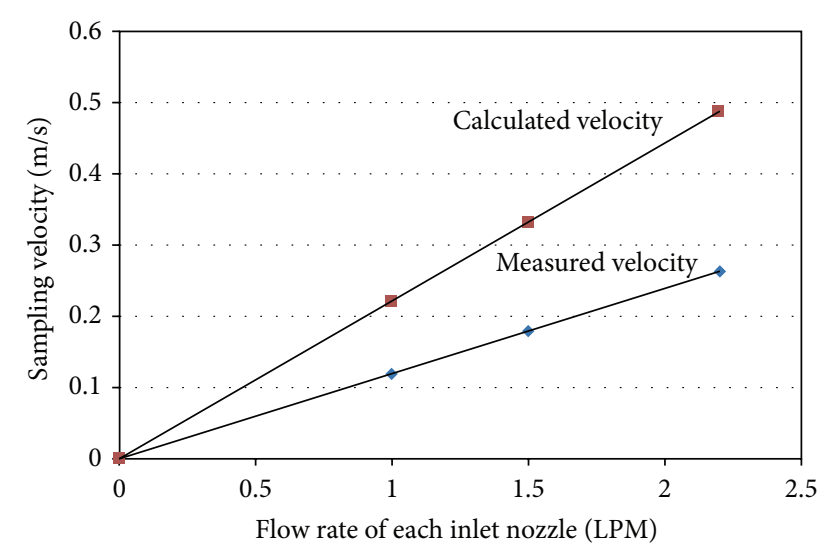

FIGURE 9: Comparison of the calculated velocity (area-averaged velocity at the inlet nozzle) and the measured velociy (maximum velocity downsteam of jets).

of the cross-sectional plane results in an inaccurate velocity measurement. Thus, to enhance the performance of the PIV measurement, we are considering that the measurement area is focused on a local region rather than on the whole region of the cross-sectional plane, and the laser beam is split to reduce the area of the shadow regions.

The area-averaged velocity at the inlet nozzle is calculated for each inlet flow rate and compared with the maximum velocity measured by the PIV in Figure 9. Since the inlet jets slow down as they go upward along the tank wall and the measurement cannot capture the rapid velocity change near the exit of the inlet nozzle, the maximum velocity measured downstream of the inlet jets is much smaller than the areaaveraged velocity at the inlet nozzle. However, the linear increase of the measured velocity with an increase of the inlet flow rate is shown well in Figure 9.

4.2. Temperature Measurement. The LIF technique [9] is used to measure the temperature field in the $1 / 40$ scaled-down moderator tank. The measurement arrangement for the LIF is the same as that for the PIV. A one-color method is applied for the LIF measurement. Heat is not added to the model during the LIF measurement. Therefore, the water temperature is uniform throughout the tank and is the same as the inlet water temperature.

Figure 10 shows the variation of the light intensity captured by a camera with water temperature. Water with Rhodamine B dye is illuminated by a $532 \mathrm{~nm}$ Nd-Yag laser sheet. The water temperature is controlled in the range of $20 \sim 35^{\circ} \mathrm{C}$, with an uncertainty of $\pm 0.1^{\circ} \mathrm{C}$. To obtain the relation between the temperature and light intensity, T-type thermocouples $\left( \pm 0.2^{\circ} \mathrm{C}\right)$ are used. Figure 10 shows the linear trend of the fluorescence intensity with the water temperature.

Figure 11 shows the temperature distribution in the cross-sectional plane. The temperature distribution is reconstructed by the calibration curve shown in Figure 10. Since the temperature is determined by the scattered light intensity, it is of vital importance to secure the uniform illumination. The results show the spatial temperature variation even though

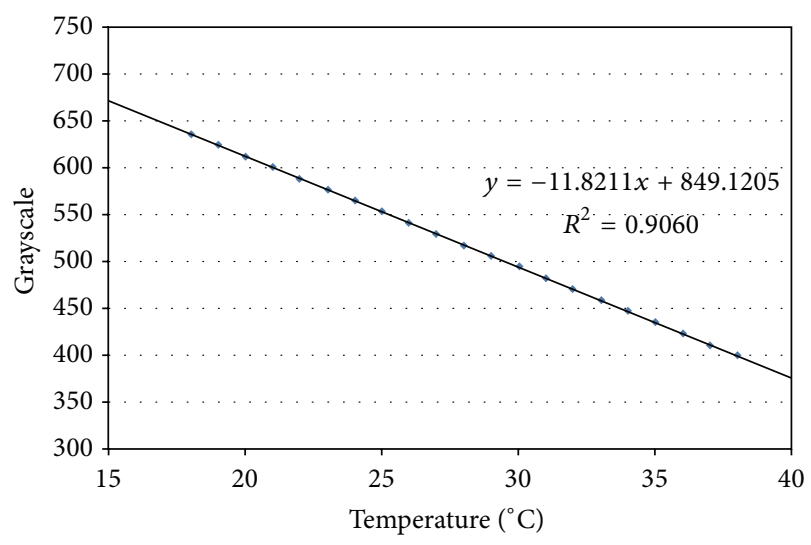

FIgURE 10: Temperature calibration with LIF measurement.

the water temperature is uniform. This unphysical result originates from the shadows by the tubes. Therefore, we will make use of a beam-splitting technique or measure the temperature field in local regions. In addition, the LIF measurement will be validated against the local temperature measurement by thermocouples.

\section{Conclusions}

A 1/40 small-scale of moderator circulation test is performed to identify the potential problems of the flow visualization and measurement expected in the 1/4 scale of MCT facility.

Prior to the experiment, a preliminary CFD analysis is performed to find out the flow, thermal, and heating boundary conditions with which the various flow patterns in the prototype CANDU-6 moderator tank can be reproduced in the experiment. If the same Ar number as the prototype is preserved, the mixed-type of flow pattern observed in the CANDU-6 moderator tank during normal operation conditions is reproduced by the CFD simulation. It is shown that the various flow patterns arising from complex interaction between the buoyancy and the inertia forces can be simulated in the 1/40 scaled-down test according to the ratio of the flow and heating boundary conditions.

In the present experiment the flow and temperature fields are measured using the PIV and LIF, respectively. These two techniques are based on optical methodologies. In particular, the key point is to illuminate the region of interest as uniformly as possible. In the present model, 12 tubes inside the tank deteriorate the image quality. As a result, the velocity and temperature fields in the shadow regions are unphysical and unbelievable, and this limitation must be avoided. The lack of tracing particles in the shadow regions as well as a curvature of the tank wall in the upper and lower part of the cross-sectional plane results in an inaccurate velocity measurement. Hence, more effort is needed to secure the uniform illumination using a beam-splitting method, or measurements are to be done for local regions.

The momentum dominant flow pattern is reproduced in the experiment since the flow boundary condition used in the 

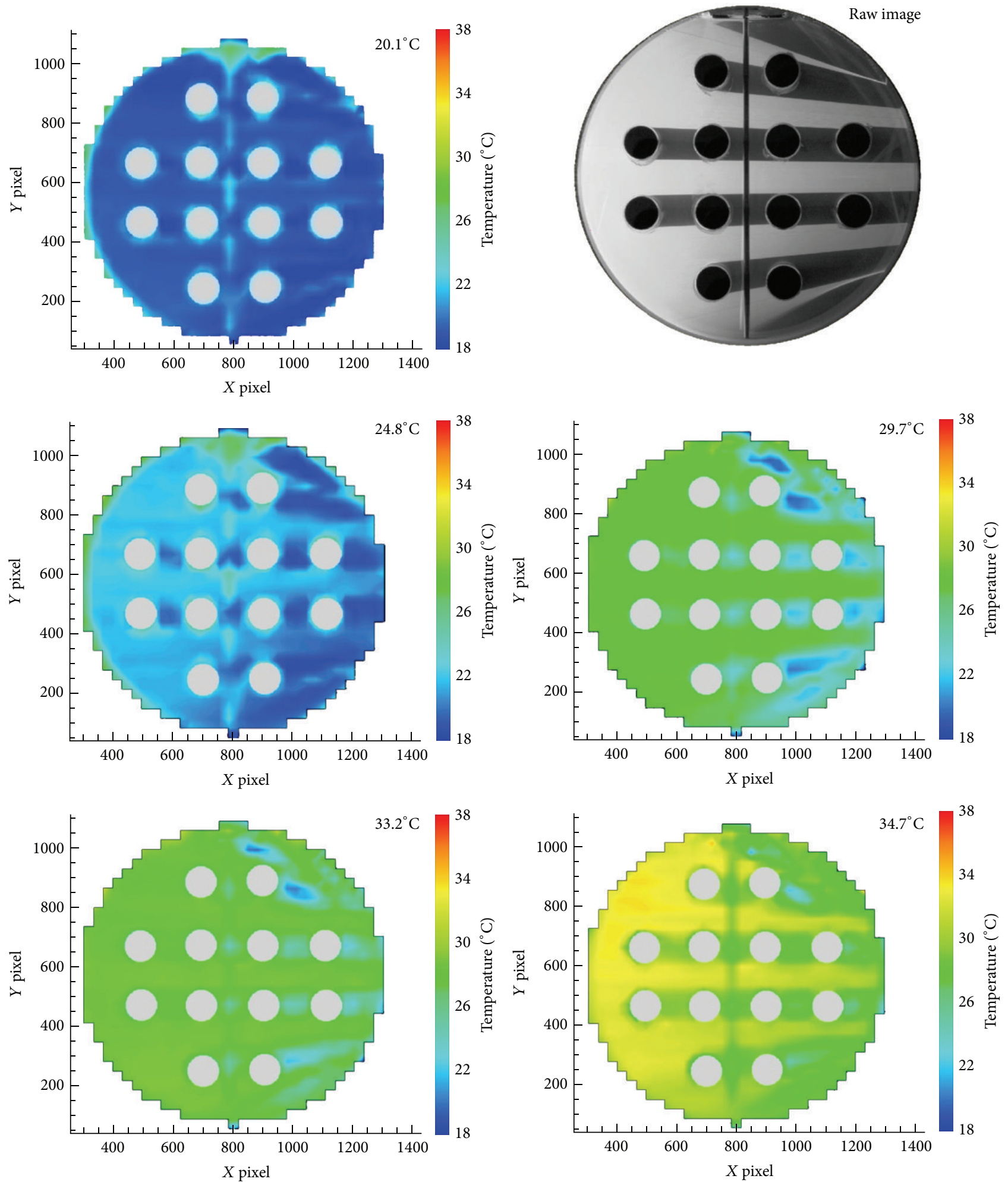

FIGURE 11: Variation of temperature measurements with different inlet water temperatures.

experiment is similar to that used in the CFD prediction of the same flow pattern. It is observed that the water jets from the two inlet nozzles move up along the tank wall to the top and collide with each other, creating a stagnation point at the top of the tank. On the whole, the flow is symmetric; there are two counter-rotating flows. For other flow patterns the measurements of velocity and temperature distribution will be compared with the CFD predictions in the future work. 


\section{Conflict of Interests}

The authors declare that there is no conflict of interests regarding the publication of this paper.

\section{Acknowledgments}

This work was supported by the National Research Foundation of Korea (NRF) grant funded by the Korea government (Ministry of Science, ICT, and Future Planning) (no. NRF2012M2A8A4025964).

\section{References}

[1] H. Z. Fan, R. Aboud, P. Neal, and T. Nitheanandan, "Enhancement of the moderator subcooling margin using glass-peened calandria tubes in CANDU reactors," in Proceedings of the 30th Annual Canadian Nuclear Society Conference, pp. 2150-2163, Calgary, Canada, June 2009.

[2] G. E. Gillespie, "An experimental investigation of heat transfer from a reactor fuel channel: to surrounding water," in Proceedings of the 2nd Annual Conf. Canadian Nuclear Society, Ottawa, Canada, 1981.

[3] H. T. Kim, B. W. Rhee, J. E. Cha, and H. L. Choi, "Status of moderator circulation test at Korea atomic energy research institute," in Proceedings of the Korea Nuclear Society Spring Meeting, Gwangju, Republic of Korea, 2013.

[4] C. D. Meinhart, S. T. Wereley, and J. G. Santiago, "A PIV algorithm for estimating time-averaged velocity fields," Transactions of the ASME, Journal of Fluids Engineering, vol. 122, no. 2, pp. 285-289, 2000.

[5] New Wave Research, Solo PIV Nd:YAG Laser System Operator's Manual, New Wave Research, Fremont, Calif, USA, 2013.

[6] ANSYS, ANSYS CFX-13.0 User Manual (Embedded in the Software Package), ANSYS, Canonsburg, Pa, USA, 2011.

[7] H. F. Khartabil, W. W. Inch, J. Szymanski, D. Novog, V. Tavasoli, and J. Mackinnon, "Three-dimensional moderator circulation experimental program for validation of CFD code MODTURCCLAS," in Proceedings of the 21st CNS Nuclear Simulation Symposium, Ottawa, Canada, September 2000.

[8] "Moderator analysis for in-core and out-of-core loss of coolant accident (LOCA)," Analysis Report 59RF-03500-AR052, KHNP, 2009.

[9] H. J. Seuntiëns, R. N. Kieft, C. C. M. Rindt, and A. A. van Steenhoven, " $2 \mathrm{D}$ temperature measurements in the wake of a heated cylinder using LIF," Experiments in Fluids, vol. 31, no. 5, pp. 588-595, 2001. 


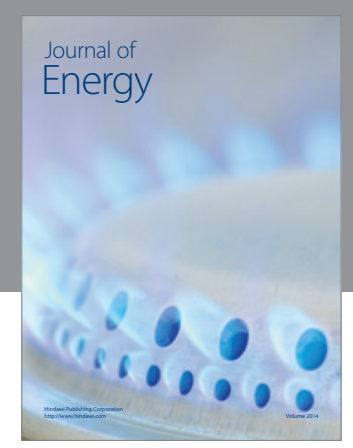

Journal of

Industrial Engineering
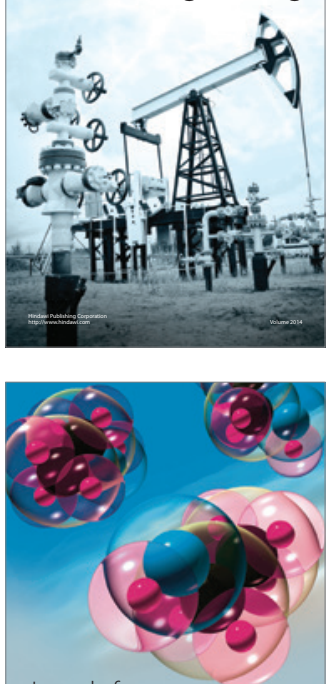

Fuels
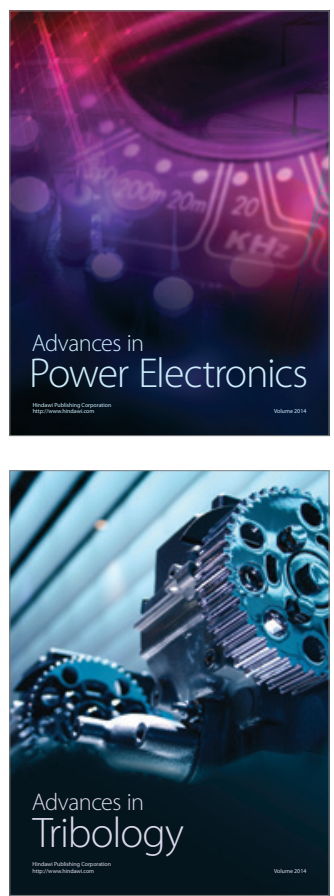

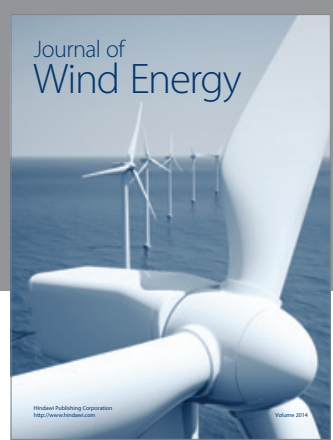

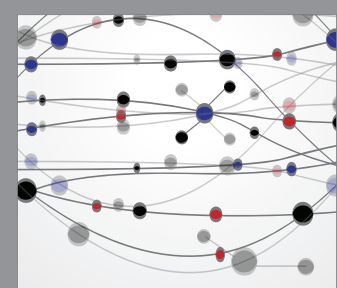

The Scientific World Journal

Submit your manuscripts at http://www.hindawi.com

Journal of

Structures
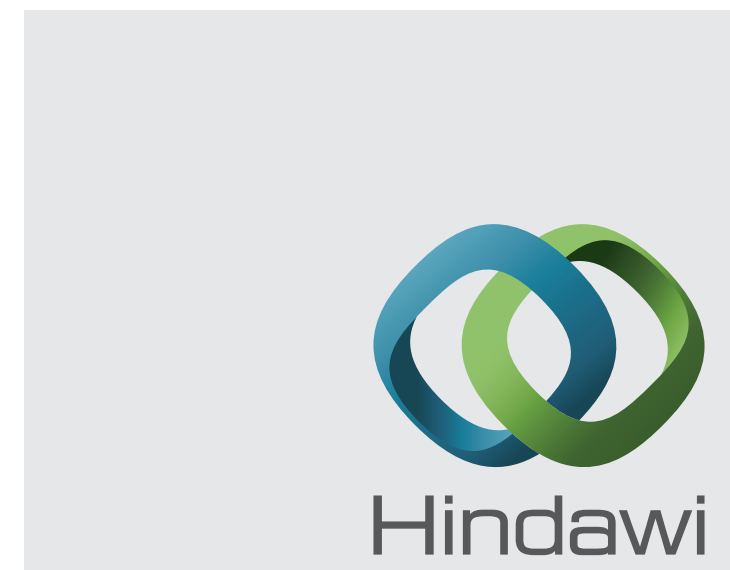

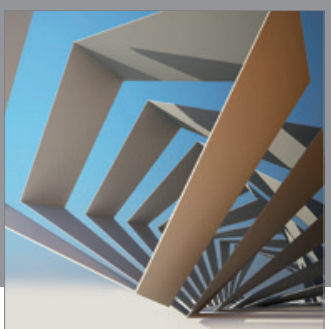

Rotating

Machinery
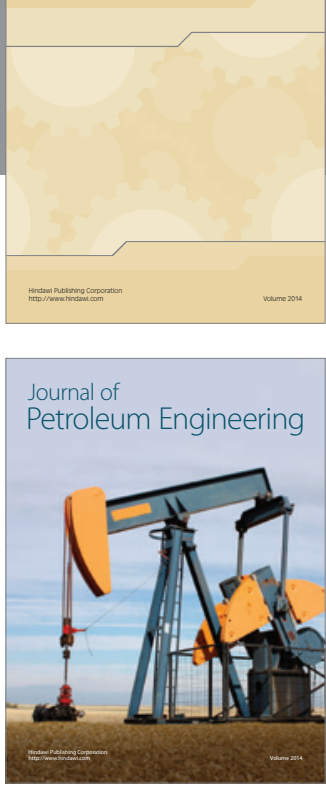

Journal of

Solar Energy
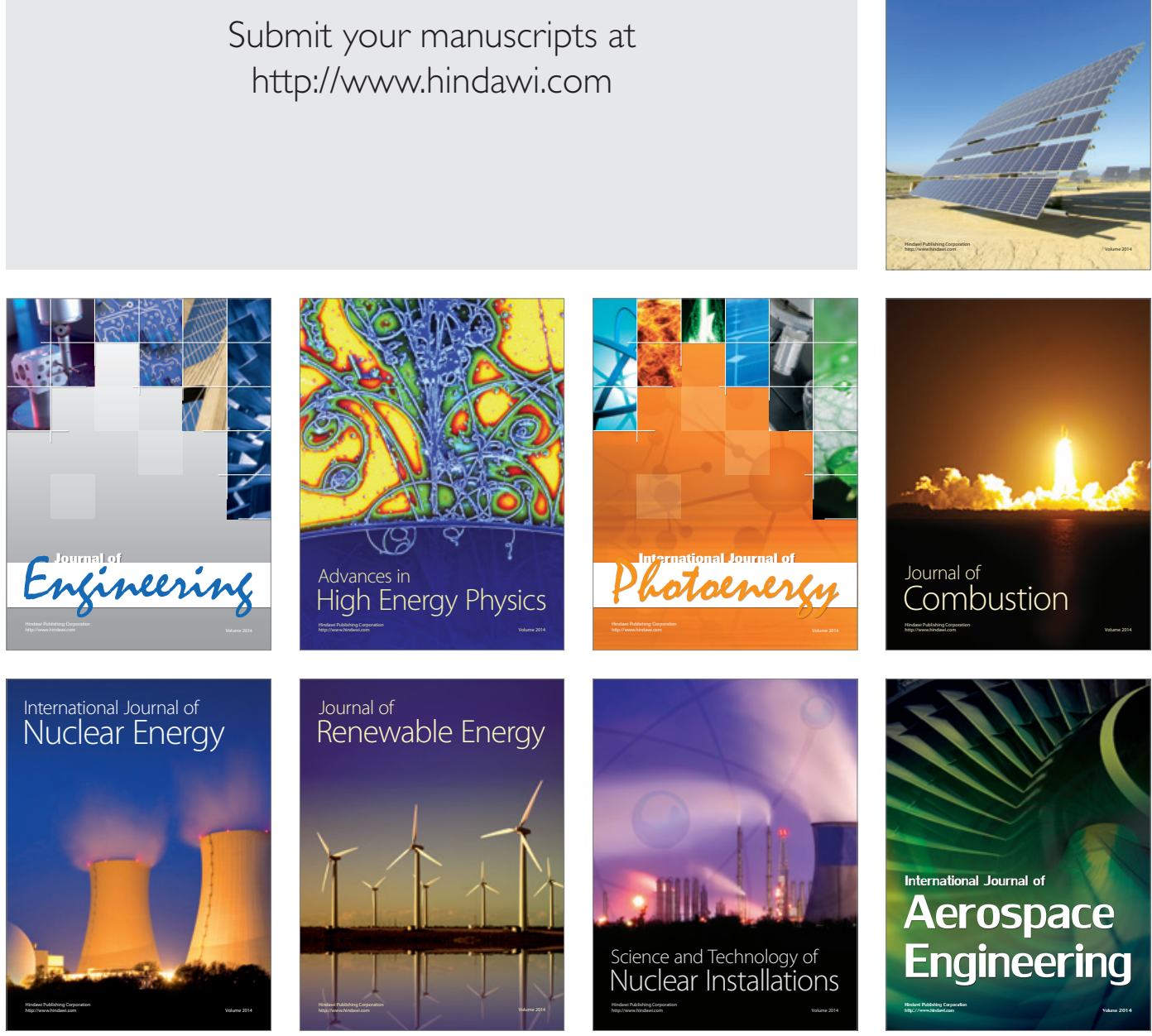